\title{
A Comparison between Literature and Film Text of Raise the Red Lantern
}

\author{
Guannan E \\ School of Fashion and Communication \\ Beijing Institute of Fashion Technology \\ Beijing, China
}

\author{
Jing Yi \\ Management Department \\ Beijing Film Academy \\ Beijing, China
}

\begin{abstract}
Wives and Concubines, a novel written by $\mathrm{Su}$ Tong, expresses the tragedy of a woman, the corruption of a system, and the struggle for some desires. According to the adaptation principles of creativity and allegorization, Zhang Yimou dissociated the narrative time and space from the background of social history, constructed a close and stable space-time cage, and completed allegorized rewriting for the original work under post-colonial context. Success of this film not only lies in the connotation provided by the original work, but also in the director's keen perception for cultural context as well as the accurate audience and theme positioning. Through creative adaptation, the director constructed the bizarre folk custom in the East at perceptual level and national allegory at rational level, to display the inborn hostility and furious struggle among women in a big traditional family with wives and concubines in flocks and to express reflection on traditional culture and attention to human nature. In this paper, comparison and analysis will be made between literary language and film language of Wives and Concubines and Raise the Red Lantern from 7 aspects covering scene, symbolic image, plot setting, narrative, etc.
\end{abstract}

Keywords-film adaptation; symbol; post-colonial context

\section{INTRODUCTION}

Raise the Red Lantern (1991) directed by Zhang Yimou, the 5th generation of famous director in China, was adapted from the medium-length novel Wives and Concubines written by $\mathrm{Su}$ Tong. By following the rewriting strategy of "creativity" and "extremalization", creating folk custom spectacle in the East at perceptual level, and constructing national allegory at rational level, he has shortened the distance between nation and the world.

Zhang Yimou has successfully broken through the complete literary narrative pressure of $\mathrm{Su}$ Tong and formed the distinct and unique creation style of this film. Besides, during the process of adapting the original manuscript, according to the creation principle of decomposability aesthetics, Zhang Yimou removed branches and tendrils. Plots with intense conflicts have been combined together, to make the film structure compact. As a result, with ups and downs, the plot is attractive and the figures possess remarkable characteristics.

In the following part, comparison will be made between literature text and film text of this film.

\section{LITERARY WORKS AND FILM ADAPT ATIONS}

\section{A. Scene Change}

Scene change leaves a deep impression on people in terms of comparis on between the novel and film.

The plot site of Wives and Concubines is set in a courtyard of Jiangnan - Chen's garden, Moon Gate, south wing-room in back garden, cherry-apple tree, pomegranate, ancient well, and pergola. The author has created an oppressive, narrow and chokey atmosphere through depressive and gloomy tones like "purple" (Chinese wisteria), "black (blood)", "blue" (well water) and "pale" (moonlight). Description of these objects is always blurry, like freehand brushwork; they hide in the thin but immense smog depicted by the author.

Compared with the novel, the film is fiercer. The film has transformed Chen's courtyard from Jiangnan Watertown to the dry northwest inland. In the film, all possible arrangements that can make the space gentle have been removed. No green plants can be seen, and only a large area of gray buildings with closed high walls stands there. Several small courtyards and dry loess in northwest regions are arranged orderly. Rigidness, grimness and closeness of the house symbolize the patriarchal clan system separated from the outside world, and violators who step out of this order will be bound to receive the punishment of death.

Scene positioning of the film has constructed a grimmer and more closed atmosphere. Though there are some losses in terms of the spirit offered by the original novel and the nutritious and inexplicit hotbed has disappeared, but the extremely closed and bleak house design has provided a depressive environment composed of besieged city that people cannot walk out and the nightmare that cannot be eliminated for the film.

\section{B. Symbol: Well and Red Lantern}

The novel Wives and Concubines creates a bleak atmosphere by depicting the ancient well and rendering the image of ancient well, which highlights the gloom and repression of Chen's house. In the work, the image of "well" appears for several times, it not only has the significance of token, but also possesses the meaning in structure. It drives 
development of the plot; as an intermediary of scene change, time lapse and plot change, it combines seemingly trivial events together. The fence surrounded by the character of "well" emblems the tragic fate of the entire mankind in such living environment.

In the novel, "red lantern" only appears for two times. However, Raise the Red Lantern centers on the eye-catching image of "red lantern" for vociferous advocacy and ritualization treatment, so as to capture the audience in vision and provide impact for audience in audition and sense. The rite of "lantern on - lantern off - sealing lantern" is the "spectacle rite" deliberately designed by Zhang Yimou for the big family with wives and concubines in flocks and internal conflict. Chase of the male master among his wives and concubines and open or secret struggle launched by women to strive for favor develop from the half-hidden state into an open and visible state. This set of tedious and rigorous rites has formed a completely external power exertion form. Meanwhile, the film also creates a space with intense visual and auditory impact through the closed scene, static and depressive layout, colors with intense contrast, and special sound setting. Thus, the folk custom spectacle of "lantern on - lantern off - sealing lantern" is displayed bombastically.

Folk custom here is a strategy rather than reality, and it is spectacle containing various complex desires. Such type has provided an effective measure for Chinese film directors to fill up the wide gap between artistry and commerce as well as nation and the world in film. Meanwhile, it has also found the possibility of obtaining world opinion and support from transnational capitals as well as bearing ideological pressure.

\section{Plot Change}

Film is the art of time, so it needs to narrate a changing and concluding story in a certain time, so as to attract audiences. Therefore, when the novel is adapted into film, the director also changes some story settings and plots. Characters in the novel are people with complex personality and multiple emotions. They have self- consciousness and take actions according to their own consciousness. Characters in the narrative works promote narrative through the mode of "personality - self-conscious will - primitive power-action"; new personality traits are verified or formed again during the narrative process. In this way, after the narrative is completed, character personalities will be fully exposed. However, in the film, character personality is single, so single self-conscious will and primitive power is formed and then single action is sent out. Therefore, Lotus who possesses countless unique feelings and personal pursuit is replaced by a tragic female character that ceaselessly struggles for the right to light the lantern but finally fails. As for Chen Zuoqian, Zhang Yimou does not give him any chance to "show his face". He often turns his side or back to audiences or appears at the edge of picture frame with midlength shot and full-length shot. Audiences cannot see Chen Zuoqian's face from beginning to end. He is the token for power and metaphor for oppressor. The film replaces care for specific people with abstract token for man. Thus, human being is changed into a symbol mark and a prop of red lantern world.

The film has brought the plots of open and secret struggles and intrigues among wives and concubines together, to make the plot conflicts follow each other successively and strengthen gradually. Meanwhile, these conflicts are interrelated to each other. In the film, Lotus pretends to be pregnant so as to consolidate her position, which is not mentioned in the novel. This plot provides great ups and downs for Lotus' life. The disclosure of false pregnancy makes her fall from the peak to the valley and her position suffers a disastrous decline. Thus, Lotus is sullen all day and reveals the personal relationship between Coral and Doctor Gao in drunkenness. As a result, Coral dies distressingly. However, in the novel, Coral's death is totally caused by Cloud, irrelevant to Lotus. Modification of film plot has increased Lotus' mental stress and meanwhile reflected cruelty of struggle in Chen's house. Even unmeant disclosure is sufficient to let the opponent catch your weakness and kill you. This also lays a foundation for the madness of Lotus. In order to express contradictions among wives and concubines in a concentrated way, exchange between Lotus and the master's eldest son Feipu as well as descriptions about daily life are deleted in the film.

However, the description about "sex" is totally externalized as the rite of "lantern on" in the film. The room with lantern on is the place where Chen Zuoqian sleeps. Lantern is raised high as the beacon of sexual desire, which means legal indulgence of sexual desire. However, other still rooms in the dark undergo closeness and repression. Adultery between the third mistress Coral is also satisfaction for sexual desire, but there is a lack of legality represented by the lantern, so the cost of life has to be paid. Lotus finally falls into disfavor for her lantern is sealed owing to the false pregnancy. In another word, the lantern that symbolizes legality of sexual desire is sealed by a piece of black cloth. However, in the novel, it is caused by loss of Chen Zuoqian's sexual function.

\section{Transformation of Narrative Perspective}

Selection of narrative perspective affects narrative style, technique and rhythm of the entire narrative text. As the base point of constructing narrative text, it can lead readers to the narrative world built in a language form. Wives and Concubines is narrated in the third person and the narrating ego is relatively hidden in third-person. The narrating ego can control the overall situation and depict people and things in the story in panorama, so it is almost omniscient and omnipotent. Besides the description focus lens can also aim at a certain character and show inner activities of this character. At this time, panoramic perspective for the story will give way to conscious activities of the characters.

However, in the film Raise the Red Lantern, objective perspective is dominant and subjective perspective is auxiliary. Application of objective perspective is the major means of completing film narrative. It organizes the narrative by adopting an objective angle not easy to perceive, so narration of both people and things is elusive. Through the 
camera, we see a black gray stern and orderly courtyard surrounded by four high walls. The courtyard also contains small yards and there are low walls in the high walls. At first, Lotus does not understand and is unfamiliar with the rules of lantern on, massaging legs, and ordering dishes, then she completely enters such system, and finally Lotus becomes a vindicator for the system. The detached and silent mode of objective perspective endows various "rules" in the courtyard with a kind of external rationality and authenticity. The film fully expresses repression and tediousness of Chen's courtyard by applying such objective perspective. Besides, it also vividly depicts rites of lantern on, lantern off, sealing lantern, and massaging legs, and turns struggle among wives and concubines in Chen's house into an allegory of striving for power.

The subjective perspective of Lotus is occasionally arranged in the film, and the camera tries to simulate the perspective of Lotus. For instance, Lotus sees servants throw Coral into the death house. After the servants leave, she walks toward the death house. At this time, the shocked face of Lotus and the shaking death house alternate on the screen. The scene trembles uncontrollably, trying to show the inner shiver of Lotus. As for the terror of personally seeing the horrific truth of "a cannibal society", this is a scene with intense subjective color - death house shaking in the eyes of Lotus. She is greatly shocked and terrified in her heart, and she possesses a presentiment for something. Her heart is full of terror as well as self-accusation for her words in drunkenness. Here application of subjective perspective is supplement for objective perspective, to make the text take in the story contents more extensively.

\section{E. Transformation of Narrative Structure}

The novel Wives and Concubines is in a prosaic structure, without prominent central plot and obvious concentrated conflict. By setting time as the narrative order, it unfolds the life process of all people in Chen's house by centering on Lotus. Like narrating trivial matters optionally and approximate to a daily record, it unfolds everything in Chen's house one by one. But actually, all things are related in essence though scattered in form. By setting emotional change of Lotus as the main line and centering on a series of images like the ancient abandoned well, Chinese wisteria and mysterious dream, through the mysterious perception of the heroine for women's life, the novel reveals the life process in which a woman is chosen as concubine, enters the feudal family with wives and concubines striving for favor, then feels downhearted and hopeless after a series of measures cannot gain recompense, and finally quit striving for favor in an insane form. During this period, Chen Zuoqian, his three mistresses, Feipu and Swallow constitute her entire living environment. The methods of chronological narrative, interleave and flashback are adopted to illustrate the life experience of Lotus. The story of "well" and the destiny of Coral have a clear order; meanwhile it is circuitous and full of tension, with exotica in ordinary.

However, owing to the limitation of time, film has to delete many tedious things, which means to give up blurry exotic points as well as characters and events that have tiny effect on overall development of the story in the novel, so as to tell a story with clear context in the restricted time. The film of Raise the Red Lantern applies the basic story frame of novel, but simplifies discursive contents into concentrated conflict. Branch contexts irre levant to theme expression are deleted and all transitions and conflicts are arranged in a single clue, so as to create a story with the classic drama structure of "origin - development - climax - ending". Such closed structure forms a complete and dramatic presumptive scene. In another word, the conflict relation always develops in a concentrated form rather than extend at synchronic level under a certain unique environment. Such plot development of single clue makes up the main body of narrative and presents a closed causal relationship.

According to the order of seas on changing, during the process of honor or dis grace change from summer of the first year to summer of the second year, the narrative is concise and compact, the plot is interrelated, and the setting is fine and ingenious. Without one flashback scene in the entire film, open and close struggles among the wives and concubines during the past several years are clearly illustrated, full of tension. The ordinal time course, event plots related to each other, and more and more poignant conflicts are drawing attention from audiences to logical relationship of the event procedure as well as to the fates of characters. Meanwhile the audiences are urged to generate expectation for final suspense of the conflict as well as to release pleasant sensation after it is ended.

In the first part (orig in) of Raise the Red Lantern, Lotus enters Chen's house. In this summer, Lotus completes the course from strangeness and curiosity for rites of lantern on and massaging legs to dependency on and addiction to the rites. In the second part (development), the arrival of "autumn" takes turns in a caption form. In the stern autumn, Lotus tries to break some crusted rules of Chen's house. For instance, she has meal in her room, generates hazy love with Feipu, falls out with Cloud after she finds out Cloud's evilness, and carries out her revenge. In the third part (climax), when "winter" comes, Lotus' lantern is sealed for she is found to pretend pregnancy. She develops from people outside the system in summer, to resistant of the system in autumn, and finally to vindicator of the system in winter, but abandoned by the system. The fourth part (ending or beginning) directly comes to "summer in the next year" by skipping spring, and the fifth mistress Bamboo enters Chen's house. In the last year, Lotus arrives here at the same time. The sadness of a tragedy lies in the endless reincarnation and the same tragedy begins at the same time in the same year.

\section{CONCLUSION}

There are two different concepts for adaptation: the first one is the concept of "loyalty" which considers that adaptation should be loyal to the original work, rather than arbitrarily change plots and details of the original work, and the adapter should maintain contents and styles of the original work; the other perspective is the concept of "creation" which thinks that adaptation is creation of brand new material and the adapter possesses full creation freedom to have different successful explanations for the same work. 
Zhang Yimou chooses the latter strategy to adapt novels, and it is extreme, allegorized and abstract adaptation. No matter what connotation a novel can provide for his film, the success of a film ultimately depends on his artistic creation and shooting approaches.

Foucault, the French philosopher once said, "What counts is the time of narrative utterance rather than the time of utterance narrative." When Zhang Yimou began to be a film director, China was in a globalization and post-colony context, so Chinese films presented dependence on and submissiveness to developed countries in the first world to some extent under this background. Chinese films seemed to realize the eye of "others" and got aware of Westerners" sight. Therefore, not a few critics consider that people like Zhang Yimou provide an easy consumption for the West and create an Eastern mirror image in Western sight through a spectacular, folkloric and exaggerated Eastern story. Zhang Yimou thinks nothing of the criticism for "post-colony" and "catering to the West". However, he indeed places himself in the reality of increasingly accelerated globalization process and energetically wants to step onto an internationalized film road. Under such context, Zhang Yimou has to face or his expected audiences are Western film viewers and Western developed countries. According to the thought of reception aesthetics, he has to consider the demands of "hidden audiences" during creation and "hidden audiences" even participate in production of film in practice.

In a series of creative practices, Zhang Yimou has inaugurated an effective internationalization strategy, to fill the gap between nation and the world and consciously or unconsciously cater to aesthetic expectation of Western audiences by displaying bizarre folk custom in the East at perceptual level and constructing national allegory at rational.

\section{ACKNOWLEDGMENT}

In this paper, the research was sponsored by the National Social Science Fund of China (Project No. 16ZD04).

\section{REFERENCES}

[1] Su Tong. Wives and Concubines[M]. The Time Literature and Art Press, 2001.

[2] (America) Fredric Jameson. Postmodernism and Cultural Theories[M].Translated by T ANG Xiaobing, Peking University Press, 1997

[3] (America) George Bluestone. Novels into Film[M]. Translated by Gao Junqian, China Film Press, 1981

[4] Huang Huilin. Folkway Sublimation: Chinese Film and National Culture[M]. Beijing Normal University Publishing Group, 1999

[5] Chen Lin. Narrative wisdom: a study of film adaptation of contemporary novels [D]. Zhejiang university, 2005. 